\title{
Intracardiac EUS-B-Guided FNA for Diagnosing Cardiac Tumors
}

\author{
Haizea Alvarez Martinez ${ }^{\mathrm{a}} \quad$ Jolanda C. Kuijvenhoven ${ }^{\mathrm{a}, \mathrm{b}} \quad$ Jouke T. Annema $^{\mathrm{a}}$ \\ aDepartment of Respiratory Medicine, Location Academic Medical Center (AMC), Amsterdam University Medical \\ Centers, Amsterdam, The Netherlands; ${ }^{\text {b}}$ Department of Respiratory Medicine, Medisch Centrum Leeuwarden, \\ Leeuwarden, The Netherlands
}

\section{Established Facts}

- Primary cardiac tumors are extremely rare.

- Obtaining a tissue sample of intracardiac masses usually requires open-heart surgery.

\section{Novel Insights}

- In 2 cases, left atrium tumors were successfully and safely sampled with endosonography using either an EBUS or a conventional EUS GI scope.

- Intracardiac Burkitt lymphoma and synovial sarcoma are extremely rare and poorly described in the literature.

- Open-heart surgery was prevented in both cases, and successful therapy was initiated, including a 7 -year survival in the lymphoma patient.

- Linear endosonography might be used for intracardiac tumor analysis in selected cases.

\section{Keywords}

Cardiac tumors · Endosonography · Esophageal endoscopic ultrasound - Esophageal endoscopic ultrasound with the EBUS scope · Synovial sarcoma · Burkitt lymphoma

\begin{abstract}
Primary cardiac tumors are extremely rare. Obtaining a tissue diagnosis is difficult and commonly requires open-heart surgery with associated morbidity. Esophageal endoscopic ultrasound (EUS) and EUS with the EBUS scope (EUS-B) provide real-time sampling of centrally located lung tumors and mediastinal lymph nodes. They also provide an excellent
\end{abstract}

view of the left atrium, since it is located adjacent to the esophagus. To date, left atrium tumor diagnostics by endosonography is poorly explored. We describe 2 exceptional diagnostic cases of left atrium tumors in which cardiac surgery was hazardous due to the clinical condition or previous surgical interventions. During EUS-B-guided fine-needle aspiration (FNA), the left atrial masses were successfully and safely sampled, revealing a Burkitt lymphoma and a synovial sarcoma. FNA including cell block analysis enabled specific

Haizea Alvarez Martinez and Jolanda C. Kuijvenhoven are the joint first authors.
(C) 2021 The Author(s).

Published by S. Karger AG, Basel

This is an Open Access article licensed under the Creative Common Attribution-NonCommercial-4.0 International License (CC BY-NC) (http://www.karger.com/Services/OpenAccessLicense), applicable to the online version of the article only. Usage and distribution for commercial purposes requires written permission. 
tumor diagnosis and molecular subtyping. Our findings suggest that in selected cases, linear endosonography qualifies as a minimally invasive technique for intracardiac tumor diagnostics.

(C) 2021 The Author(s).

Published by S. Karger AG, Basel

\section{Introduction}

Malignant primary cardiac tumors (MPCT) are extremely rare entities with a reported incidence below $0.1 \%$ of all cancers [1]. Left atrium tumors commonly obstruct the blood flow or create mitral regurgitation, simulating mitral valve diseases. The diagnosis of a suspected MPCT should be approached from different perspectives. First, imaging techniques are mandatory to determine the exact localization and extension of the lesion. For this, CT, PET-CT, cardiac MRI, and echocardiography are the commonly used techniques [2-5]. Second, intracardiac tissue sampling is challenging, and the histological diagnosis generally requires open-heart surgery with associated morbidity and mortality. However, patients are regularly not physically fit to undergo open-heart surgery or complex intravascular techniques for diagnostic purposes [6].

Linear endosonography is the first-line technique for mediastinal nodal sampling, and it is been increasingly used for centrally located lung tumor diagnosis due to the high accuracy and safety profile [7]. Although endosonography provides an excellent overview of the left atrium, its use for left atrium tumor diagnosis has barely been explored. We present 2 cases of patients with suspected MPCT in which the diagnosis was obtained in an outpatient setting by esophageal endoscopic ultrasound (EUS) with the EBUS scope (EUS-B).

\section{Case 1}

A 77-year-old female with a previous history of B-cell NHL was referred to our hospital with a solitary FDG avid mass in the left atrium on PET-CT and pericardial and pleural effusion (Fig. 1a, b). Pleural thoracocentesis was performed twice to obtain pleural fluid for cytology, but it was described as nonspecific. Pericardial cytology showed atypical cells, requiring tissue sampling for diagnosis and possible therapeutic options. Open-heart surgery for left atrium mass biopsy was judged to be very hazardous. After obtaining consent of the patient and family, it was decided to attempt an EUS-guided fine-needle aspiration (FNA) of the suspected left atrium mass. In an outpatient setting under $5 \mathrm{mg}$ midazolam, EUS was performed. Systematic mediastinal evaluation did not show any enlarged or sonographically suspicious lymph nodes. The intra-atrial mass was identified located in the roof of the left atrium near the atrium septum and at the inlet of the vena cava to the right atrium (Fig. 1c, d). The mass was sampled with a 19G $\operatorname{Cook}^{\circledR}$ (IN, USA) needle under real-time ultrasound guidance, and the aspirate was sent for cytology, cell block, and flow cytometry.

No signs of arrhythmia, bleeding, extravasate nor pericardial tamponade, or other adverse events occurred following FNA. The final diagnosis based on EUS-guided intra-atrial sampling was a malignant Burkitt lymphoma, a malignancy never before diagnosed by this diagnostic approach. Subsequently, a chemotherapy treatment consisting of R-CHOP was initiated. Seven years after diagnosis, the patient is stable, enjoying good quality of life, and there are no signs of disease recurrence at clinical and imaging follow-up.

\section{Case 2}

A 47-year-old male was referred to the respiratory endoscopy service after an irradical resection of a synovial sarcoma arising from tricuspidalis annulus with ingrowth in the atrium septum. Previously, a tricuspid valve plastia and annuloplasty with ring was performed. A CT scan of the chest and an MRI of the heart showed abnormalities inside and around both the atria (Fig. 2a, b). Obtaining a tissue was indicated to differentiate between a postsurgical hematoma and tumor recurrence. However, performing a repeat thoracotomy and open-heart surgery was judged to be extremely complicated due to the prior surgery.

As an alternative of a rethoracotomy, bronchoscopy + EBUS/ TBNA and EUS-B were performed under propofol sedation. At endobronchial ultrasound, a lesion in the hilum of the right lung was identified compatible with - and confirmed by aspiration - a postsurgical hematoma (Fig. 2a, b [H]). Following EBUS, the scope was introduced into the esophagus (EUS-B) since the intracardiac mass was not visible from the airways. From the esophagus, a large inhomogeneous mass was visualized on the ultrasound image, occluding over half of the left atrium. On strain elastography imaging, the mass seemed to be consisted of different rigidities. Under real-time ultrasound guidance, 4 FNA samples were taken with a $22 \mathrm{G} \mathrm{Cook}{ }^{\circledR}$ (IN, USA) needle for cytology, cell block, and culture. There were no signs of arrhythmia, bleeding, extravasate, or other complications. Onsite cytology showed malignant tumor cells, and the final diagnosis demonstrated the recurrence of the previous synovial sarcoma in the left atrium.

\section{Discussion}

We demonstrated that endosonography, both with the regular EUS and smaller EBUS scope, with real-time sampling of left atrium tumors was feasible and safe. In both cases, cytology and cell block analysis provided a clear diagnosis, including the necessary immunohistochemistry.

In the first case, an intracardiac Burkitt lymphoma was diagnosed after an EUS procedure. A few cases of intra- 

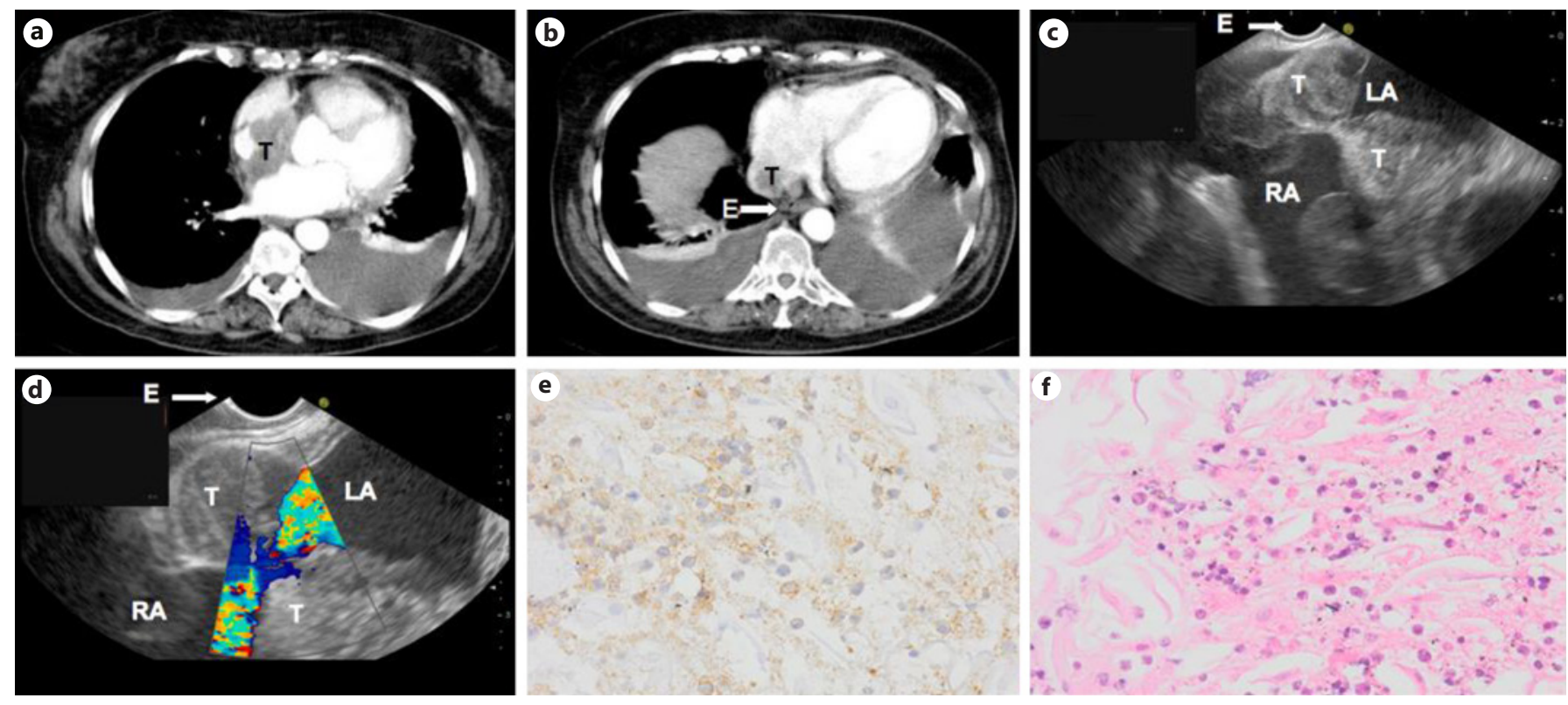

Fig. 1. a, b CT scan of the thorax showing a tumor (T) inside the left atrium, adjacent to the esophagus (E) and a bilateral pleural effusion. c, d EUS images showing the tumor (T) located inside the left atrium (LA) near to the entrance of the right atrium (RA). e, f 19G FNA cytology samples showing cells with enlarged nuclei, little cytoplasm, and some clear nucleolus with blastair aspect, positive for CD20 strain, compatible with Burkitt lymphoma. EUS, endoscopic ultrasound; FNA, fine-needle aspiration.
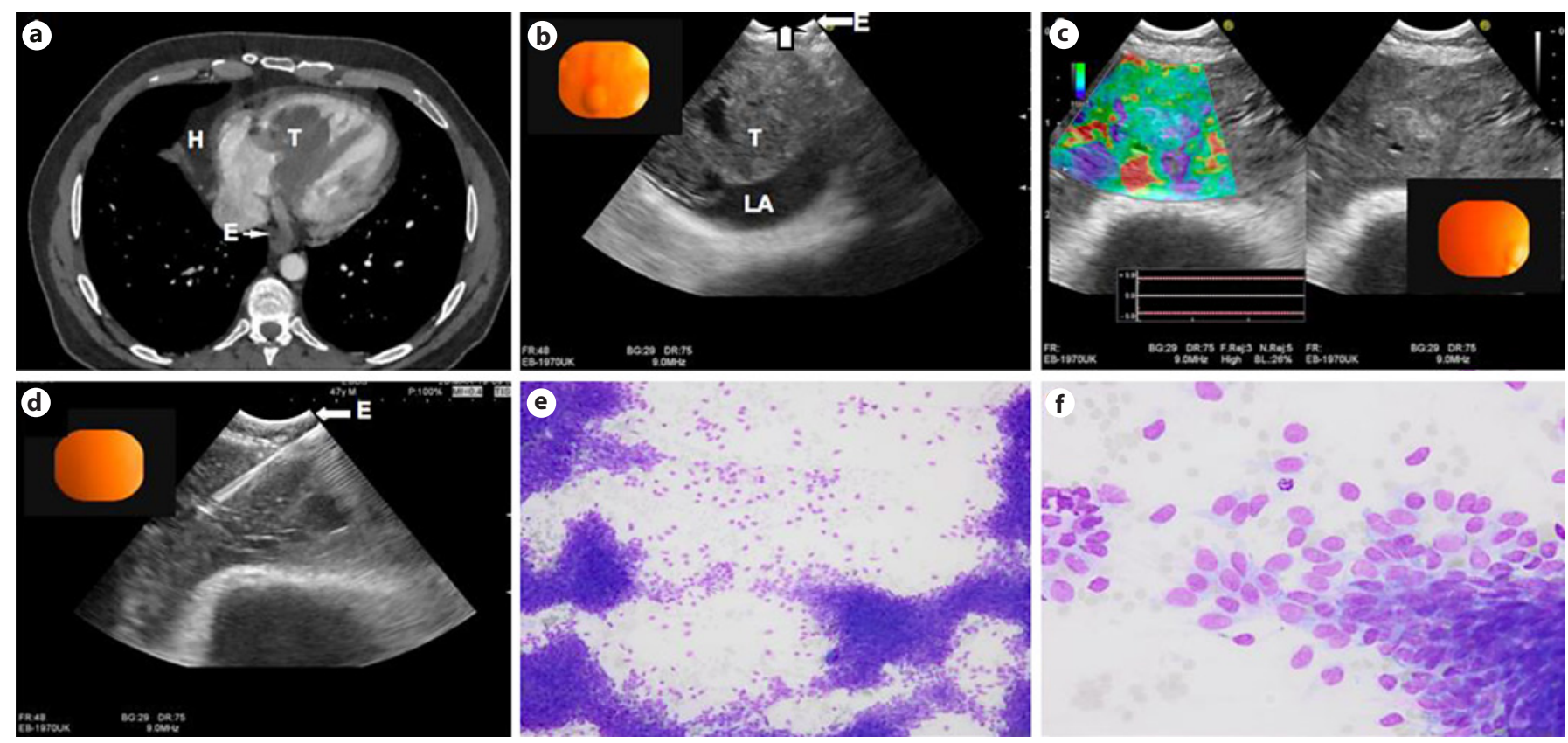

Fig. 2. a CT scan of the thorax showing a hematoma (H) adjacent to the right atrium and a tumor $(\mathrm{T})$ in the left atrium, adjacent to the esophagus (E). b EUS-B image (EBUS scope) showing the tumor (T) inside the left atrium (LA). c Elastography pattern of the tumor located in the left atrium showing the different densities of the tumor. d EUS-B FNA of a $22 \mathrm{G}$ needle inside the tumor. e, f $22 \mathrm{G}$ FNA cytology samples demonstrating high cellularity with loose and atypical cells located in a bundle group connection with spool cellular aspect and naked cores, compatible with synovial sarcoma. FNA, fine-needle aspiration. 
cardiac Burkitt lymphomas are described [8]. However, this is the first case diagnosed by endosonography. EUSguided diagnosis of digestive Burkitt lymphomas has been described before $[9,10]$. In the described case, the minimally invasive endosonographic approach was extremely important as the patient was judged to be fragile for diagnostic surgery.

In the second case, intra-atrial recurrence of a synovial sarcoma diagnosis was made by the EUS-B FNA approach and the help of elastography. Elastography shows the rigidity pattern of lesions helping to choose the optimal place to take the samples and avoid necrotic areas, and it has been demonstrated that it is helpful in predicting lymph node malignancy in lung cancer patients [11]. Elastography was helpful to reassure the suspicion of a malignant lesion in the left atrium and to take the tissue sample in the most suspicious place. Also, in this case, a resurgical approach with tissue sampling was not a feasible option due to the previous surgery. As synovial sarcomas have a poor prognosis, the prompt diagnosis led to a rapid chemotherapy treatment, and the patient is still alive after a 2-year follow-up. There are very few reports in the literature about synovial sarcomas diagnosed by EUS [12].

The literature regarding EUS or EUS-B diagnostic procedures of cardiac tumors [13-15], especially in the left atrium $[16,17]$, is scarce and very uncommon. Linear endosonography by EBUS/EUS-B is incorporated in the guidelines for diagnosing and staging of lung cancer [18] as the initial diagnostic test for mediastinal tissue acquisition. It has also been shown that lung tumor sampling from the esophagus and the airways is feasible and safe [7, 19]. The diagnostic utility of endosonography is constantly growing, as it has demonstrated its utility for the assessment of the mediastinal/vascular invasion (T4) in patients with centrally located lung lesions [20].

Even if it is not a common procedure, there are reports in the literature showing the possibility of using endosonography for transvascular biopsies of intrathoracic le- sions that could not be reached otherwise [21]. Transaortic approaches are feasible in selected cases for para-aortic tumors or lymph nodes [22].

It should be clear that only very selected cases might be eligible for these kind of diagnostic approaches. Operators should be experienced, and alternative diagnostic approaches should be carefully reviewed. In conclusion, in very selected cases, skilled operators can use EUS-B FNA as a minimally invasive procedure for the diagnosis of intracardiac/left atrial tumors.

\section{Acknowledgment}

We acknowledge the contribution made by Robert Hoogvorst (Cyto technician at Amsterdam UMC, location AMC) in the pathologic interpretation and Dr. I. A. H. Van der Berk (Consultant Radiologist at Amsterdam UMC, location AMC) in the interpretation of radiology images.

\section{Statement of Ethics}

Written informed consent was obtained from the patient for publication of this case report and any accompanying images.

\section{Conflict of Interest Statement}

The authors have nothing to declare.

\section{Funding Sources}

There was no funding.

\section{Author Contributions}

H.A.M. and J.K. wrote the manuscript, which was then reviewed by all coauthors.

\section{References}

1 Reynen K. Frequency of primary tumors of the heart. Am J Cardiol. 1996;77:107.

2 European Cooperative Study Group; Engberding R, Daniel WG, Erbel R, Kasper W, Lestuzzi C, Curtius JM, et al. Diagnosis of heart tumours by transoesophageal echocardiography: a multicentre study in 154 patients. Eur Heart J. 1993;14:1223.
3 Gilkeson RC, Chiles C. MR evaluation of cardiac and pericardial malignancy. Magn Reson Imaging Clin N Am. 2003;11:173-86, viii.

4 Mousavi N, Cheezum MK, Aghayev A, Padera R, Vita T, Steigner M, et al. Assessment of cardiac masses by cardiac magnetic resonance imaging: histological correlation and clinical outcomes. J Am Heart Assoc. 2019;8(1): e007829.
5 Hoey ET, Mankad K, Puppala S, Gopalan D, Sivananthan MU. MRI and CT appearances of cardiac tumours in adults. Clin Radiol. 2009;64:1214.

6 Takashima A, Ogata T, Yamada H, Wakatsuki $T$, Sata $M$. Intracardiac echocardiography-guided biopsy of a lipomatous cardiac tumor arising from the interatrial septum. Circ J. 2017;81:1553-5. 
7 Kuijvenhoven JC, Fausto L, Crombag LC, Spijker R, Bonta PI, et al. Endobronchial ultrasound for the diagnosis of centrally located lung tumors: a systematic review and metaanalysis. Respiration. 2019 Nov;99(5):1-10.

8 Koca Yozgat A, Ozyoruk D, Kacar D, Cetin II, Yaman Bajin I, Inan K, et al. Burkitt lymphoma presenting with intracardiac mass and tumor thrombosis in the anterior mediastinum with literature review. J Pediatr Hematol Oncol. 2019 Apr;41(3):e197-200.

9 Hamabata T, Umeda K, Noudomi S, Daifu T, Morishima T, Saida S, et al. Utility of endoscopic ultrasound-guided fine needle aspiration for diagnosis of Burkitt lymphoma in two pediatric cases. Rinsho Ketsueki. 2013 Jul; 54(7):653-7.

10 Nakaji S, Hirata N, Yoshimura S, Shiratori T, Kobayashi M, Ishii E, et al. A case of primary pancreatic Burkitt's lymphoma diagnosed by EUS-guided FNA. Gastrointest Endosc. 2013 Jun;77(6):958-9.

11 Verhoeven RLJ, de Korte CL, van der Heijden EHFM. Optimal endobronchial ultrasound strain elastography assesment strategy: an explorative study. Respiration. 2019;97:337-47.
12 Inage T, Nakajima T, Sata Y, Fujiwara T, Iwasawa $S$, Takiguchi $Y$, et al. Intracardiac tumors with extracardiac extension diagnosed by endoscopic ultrasound with bronchoscopeguided fine-needle aspiration. Ann Thorac Surg. 2019 Jan;107(1):e5-7.

13 Vilmann P, Clementsen PF, Colella S, Siemsen M, De Leyn P, Dumonceau JM, et al. Combined endobronchial and oesophageal endosonography for the diagnosis and staging of lung cancer: European Society of Gastrointestinal Endoscopy (ESGE) Guideline, in cooperation with the European Respiratory Society (ERS) and the European Society of Thoracic Surgeons (ESTS). Eur Respir J. 2015; 46:40-60.

14 Christiansen S, Kuijvenhoven JC, Bodtger U, Naur TMH, Ahmad K, Sidhu SJ, et al. Endoscopic ultrasound with bronchoscope-guided fine needle aspiration for the diagnosis of paraesophageally located lung lesions. Respiration. 2019;97(4):277-83.

15 Kuijvenhoven JC, Livi V, Morandi L, Cancellieri A, Annema JT, Trisolini R. The expanding role of endobronchial ultrasound in patients with centrally located intrapulmonary tumors. Lung Cancer. 2019 Aug;134:194201.

16 Molina JC, Chaudry F, Menezes V, Ferraro P, Lafontaine E, Martin J, et al. Transvascular endosonographic-guided needle biopsy of intrathoracic lesions. J Cardiovasc Surg. 2020; 159(5):2057-65.
17 von Bartheld BM, Rabe KF, Annema JT Transaortic EUS-guided FNA in the diagnosis of lung tumors and lymph nodes. Gastrointest Endosc. 2009 Feb;69(2):345-9.

18 Gornals JB, de la Hera M, de Albert M, Claver E, Catala I. EUS cardiac puncture-guided right atrial tumor. Gastrointest Endosc. 2015; 82(1): 165 .

19 Moreno-Castro R, Rios-Martin JJ, GallegoGarcia de Vinuesa P, Castro-Fernandez AJ, Marques-Asin FJ, Caparros-Escudero C, et al. Pericardial tumor diagnosed by EUS-guided FNA. Gastrointest Endosc. 2009;69(3 Pt 1): 562-3.

20 Somani P, Sharma M, Patil A, Kumar A. Endoscopic ultrasound-guided fine needle aspiration of a pericardial mass. Endoscopy. 2016; 48(Suppl 1):E45-6.

21 Pesenti C, Bories E, Caillol F, Moutardier V, Monges G, Giovannini M. Cardiac rhabdomyosarcoma mimicking a mediastinal tumor and the role of endoscopic ultrasonography. Endosc Ultrasound. 2012;1(1):56-8.

22 Demirci NY, Güleryüz M, Kolay E. Primary cardiac angiosarcoma diagnosed from an Endobronchial Ultrasound (EBUS)-guided biopsy. Arch Bronconeumol. 2018;54(10):524. 